Departamento de Zoologia Médica e Parasitologia

Diretor: Prof. Dr. Z. Vaz

\title{
SÔBRE A DETERMINAÇÃO DE PEQUENAS QUANTIDADES DE CÁLCIO
}

\section{Rubens Salomé Pereira}

Docente-livre da Universidade de São Paulo

Para a determinação do cálcio, dos vários reagentes recomendados - oxalatos, fosfatos, tungstatos, ácido picrolónico, certos ácidos graxos, oxina, alizarina, complexo de nitrito de niquel, etc. - o de mais larga aceitação é, particularmente quando se encontram numerosos interferentes na solução que se analisa, sem dúvida, o primeiro dos reagentes citados, e a separação do cálcio sob forma de $(\mathrm{C} 00)_{2} \mathrm{Ca}$, apesar de certas desvantagens, é o princípio em que se baseia a maioria dos micrométodos de dosagem desse metal. Graças à sua baixa solubilidade, o $(\mathrm{C} 00)_{2} \mathrm{Ca}$ se recomenda como base de métodos para a dosagem direta, ou indireta, do cálcio. MANLY (1) resumiu em quadro interessante, os processos que mais se indicam para a microdeterminação desse elemento.

A experiência demonstra que o cálcio pode precipitar-se, de modo pràticamente completo, como oxalato, de soluções de $\mathrm{pH}=4$, ou menos ácidas e que a presença de quantidades mesmo pequenas, de ícidos fortes impede que tal separação se realize. A solubilidade do $(\mathrm{C} 00)_{2} \mathrm{Ca}$ aumenta em presença do magnésio e, para evitar essa influência desfavorável, recomenda-se o uso de largo excesso de reagente, afim de êsse elemento manter-se em solução, sob forma de sal duplo. ROBERTSON e WEBB (2), considerando a possibilidade de precipitação incompleta do cálcio como $(\mathrm{COO})_{2} \mathrm{Ca}$, verificaram que, mesmo depois de reprecipitar-se o $\mathrm{Ca}$, sob a referida forma, nas condições da técnica por êles usada, a análise espectrográfica ainda revelava a presença do magnésio no precipitado e a do cálcio na solução, apesar de haver ajuntado largo excesso de precipitante. A possibilidade de o cálcio não se separar completamente como $(\mathrm{C} 00)_{2} \mathrm{Ca}$, ainda cresce nas condições em que se diminuem os erros provenientes da coprecipitação do magnésio e do sódio, a saber: alta diluição e baixo $\mathrm{pH}$. Os citados pesquisadores, tendo em consideração que êsses erros deveriam avultar

Trabalho realizado no Departamento de Zoologia Médica e Parasitologia, da Faculdade de Medicina Veterinária da Universidade de Săo Paulo, e no Laboratório de Fisiologia Geral e Animal. do Departamento de Zoologia da Faculdnde de Filosofia, Ciências e Letras, da mesma Universidade. com o auxilio dos Fundos Universitírios de Pesquisas. 
no caso de se aumentar a quantidade de sais solúveis no líquido que se analisa, evitam o emprego de soluções "tampão".

Para se isolar o cálcio sob forma de $(\mathrm{C} 00)_{2} \mathrm{Ca}$, é necessário eliminarem-se os elementos capazes de formar oxalatos pouco solúveis, como o $\mathrm{Cu}$, o $\mathrm{Zn}$, o $\mathrm{Pb}$, etc., e os que se possam precipitar, mesmo em parte sòmente, nas condições estabelecidas pela técnica usada. Pràticamente, pois, o cálcio se deve prèviamente separar de quasi todos os metais, se se excetuarem os alcalinos e o magnésio. E' sabido, porém, que o $(\mathrm{C} 00)_{2} \mathrm{Ca}$, ao formar-se, tem a tendência de arrastar consigo os alcalinos sob forma de oxalatos, e que, precipitado por meio do $\left(\mathrm{COONH}_{4}\right)_{2}$, encerra quantidades apreciáveis dêste reagente. Nessas condições, a manganometria pode induzir a êrros e é, por isso, aconselhável, quando no líquido houver quantidades notáveis de sódio, v. g., reprecipitar-se o cálcio como $(\mathrm{COO})_{2} \mathrm{Ca}$. A influência dos metais alcalinos, porém, poderá ser eliminada se o cálcio, isolado sob forma de $(\mathrm{COO})_{2} \mathrm{Ca}$, for ulteriormente transformado em $\left(\mathrm{PO}_{4}\right)_{2} \mathrm{Ca}_{3}$.

Um dos mais sérios obstáculos à determinação do cálcio em presença do magnésio, é o fenômeno da coprecipitação dêste. Para evitar tanto quanto possível essa dificuldade, o que geralmente se aconselha é dissolver-se o precipitado de oxalatos e reprecipitar-se o cálcio tantas vezes quantas as necessárias para se obter o $(\mathrm{COO})_{2} \mathrm{Ca}$ suficientemente puro. Isso, porém, sôbre tornar excessivamente trabalhoso o processo, aumenta a possibilidade de perda de cálcio. A influência do magnésio, porém, poderá ser pràticamente eliminada, dentro de certos limites de concentração (3) se o líquido em que se acha o cálcio, e em que tambem se encontra o magnésio, for convenientemente alcalinizado antes de se precipitar o $\left(\mathrm{PO}_{4}\right)_{2} \mathrm{Ca}_{3}$.

Os interferentes que geralmente se levam em consideração no caso de que ora nos ocupamos, se se excetuar o magnésio, isto é, o alumínio, o cobre, o ferro, o manganez, etc., podem ser separados da solução em que se vai dosar o cálcio, de modo relativamente simples e rápido, por meio da 8 - hidroxiquinolina em meio acético tamponado de modo conveniente (4). Para se empregar, porém, essa marcha analítica, é indispensável evitar que o líquido em que se vai determinar o cálcio se alcalinize, pois êste metal dá, em meio amoniacal, complexo insolúvel com a oxina, propriedade que foi aproveitada por Yoshimatsu para a dosagem colorimétrica dêsse elemento (5).

A separação do cálcio em presença do magnésio por meio do método do oxalato é discutida por KoLTHOFF e SANDELL de modo exce- 
lente (6), e muito instrutivos são os trabalhos de SENDROY (7-8) sôbre a dosagem colorimétrica do primeiro dos elementos citados.

A determinação do cálcio estudada no presente trabalho, se baseia nos pontos seguintes:

1) isolamento dos interferentes precipitáveis pela oxina em meio ácido.

2) precipitação do cálcio sob forma de oxalato, em meio ácido convenientemente tamponado, por meio de modificação da técnica recomendada por HIRTH (9).

3) transformação do $(\mathrm{COO})_{2} \mathrm{Ca}$ em $\mathrm{Cl}_{2} \mathrm{Ca}$ e precipitação do $\left(\mathrm{PO}_{4}\right)_{2} \mathrm{Ca}_{3}$ (3-10-11).

4) determinação indiréta do cálcio por meio do fósforo existente no precipitado (12).

No caso do sôro de sangue humano, ou dos animais domésticos, por ex., o cálcio pode ser precipitado diretamente como $\left(\mathrm{PO}_{4}\right)_{2} \mathrm{Ca}_{3}$ à vista da pequena quantidade de magnésio presente, e da diminuta porção de outros interferentes (3-12) de sorte que o método a ser descrito pode ser grandemente simplificado, de acôrdo com as características do material que se estuda.

\section{MÉTODO}

Reagentes necessários - Além dos reagentes (a), (b), e (c), (d), (e), (f), (g), (h), descritos em trabalho anterior (13), destinados à separação dos interferentes precipitáveis em meio ácido pela oxina, ao isolamento e à lavagem do $(\mathrm{COO})_{2} \mathrm{Ca}$ precipitado de acôrdo com a técnica então descrita, os seguintes são necessários:

i) Acido clorídrico $\mathrm{d}=1.19$

j) Agua oxigenada a $30 \%$

k) Hidróxido de sódio - Solução $5 \mathrm{~N}$, isenta de carbonatos

1) Fosfato trisódico - Solução a 5 grs. per $100 \mathrm{~cm}^{3}$

m) Líquido de lavagem - Álcool etílico a $60 \%$ - 9 partes Álcool amílico . . -1 parte

O líquido se alcalinisa levemente por $(\mathrm{k})$ em presença de (a).

n) Reativo sulfo-molibdico - Num balão graduado de $500 \mathrm{~cm}^{3}$ dissolvem-se 6,25 grs. de $\mathrm{Mo}_{7} \mathrm{O}_{24}\left(\mathrm{NH}_{4}\right)_{6}, 4 \mathrm{H}_{2} \mathrm{O}$ em água distilada, à temperatura ambiente, e perfaz-se o volume marcado. Transfere-se a solução obtida para um volumétrico de $1.000 \mathrm{~cm}^{3}$ e ajuntam-se $500 \mathrm{~cm}^{3}$ de $\mathrm{SO}_{4} \mathrm{H}_{2} 10 \mathrm{~N}$.

o) Reativo sulfo-molibdico reduzido - Num frasco escuro, de rolha esmerilhada, põem-se 5 grs. de raspas, ou de lã de cobre não 
oxidado e adicionam-se $100 \mathrm{~cm}^{3}$ de $(n)$. Deixa-se em contacto durante cerca de 3 horas, pelo menos, tendo-se o cuidado de agitar-se o frasco de quando em vez.

Todos os reagentes usados devem ser do mais alto gráu de pureza, "pró analysi", e as soluções se devem conservar preferivelmente em frascos de vidro Pyrex.

$\mathrm{O}(\mathrm{COO})_{2} \mathrm{Ca}$ isolado e lavado de acôrdo com a técnica descrita em (13), dissolve-se em $0.1 \mathrm{~cm}^{3}$ de (i) e à solução ajuntam-se $0.5 \mathrm{~cm}^{3}$ de (j). Arrolha-se frouxamente o tubo de centrifugação de forma cônica e de diâmetro reduzido no terço inferior, em que se acha o $(\mathrm{COO})_{2} \mathrm{Ca}$, e mergulha-se em banho-maria fervente até que a destruição se complete, o que, em geral, leva 20-30 minutos. Obtem-se assim um líquido ácido, isento de oxalatos, e em que o cálcio se encontra sob forma de $\mathrm{C}_{2} \mathrm{Ca}$. Em presença de (a), e após se haver elevado o volume da solução para $1-2 \mathrm{~cm}^{3}$, ou mais, de acôrdo com a quantidade de Ca presente, por meio de água distilada, neutraliza-se o líquido por meio de $(\mathrm{k})$ posto às gotas, cuidadosamente, e ajuntam-se excesso dêste, na proporção de $0,15 \mathrm{~cm}^{3}$ per $\mathrm{cm}^{3}$ de solução neutralizada. Ao cabo de 5 minutos adiciona-se $1 \mathrm{~cm}^{3}$ de (1), homogeniza-se bem o conteúdo do tubo, arrolha-se êste e deixa-se em repouso durante 45-60 minutos. Centrifuga-se, então, durante 3-5 minutos, à velocidade de 2.500-3.000 r. p. m. Decanta-se o líquido sobrenadante e inverte-se o tubo sôbre camada de algodão recoberta por folha de papel de filtro, posta em copo de boca larga. Deixa-se que bem se escorra o líquido, enxuga-se a boca do tubo com o auxílio de papel de filtro sem fibras, e, por meio de pipeta de extremidade de vasamento fina, injetam-se, soprando-se a começo, afim de pôr-se o precipitado em suspensão, $5 \mathrm{~cm}^{3}$ de $(\mathrm{m})$, aproveitando-se o líquido para bem se lavarem as paredes do tubo, fazendo-se aquele, uma vez suspenso o precipitado, escorrer ao longo destas. Centrifuga-se, decanta-se, deixa-se escorrer, como anteriormente. Repetem-se as operações de lavagem. Dissolvese o precipitado assim obtido em $1 \mathrm{~cm}^{3}$ de $\mathrm{SO}_{4} \mathrm{H}_{2} \mathrm{~N}$. Adicionam-se cerca de $3 \mathrm{~cm}^{3}$ de água distilada, agita-se para tornar o líquido homogênio e em seguida, para cada $5 \mathrm{~cm}^{3}$ de volume total a ser completado ulteriormente, ajuntam-se $0.4 \mathrm{~cm}^{3}$ de (n) e $0.2 \mathrm{~cm}^{3}$ de (o). Perfaz-se então, por meio de água distilada, o volume requerido. Mergulha-se o tubo em banho-maria fervente durante 10 minutos. Deixa-se o líquido esfriar espontâneamente, refaz-se exatamente o volume desfeito pela evaporação e determina-se a extinção dada pelo fotômetro gradual de ZEISS - PULFRICH, interpondo-se o filtro S-72 e empregando-se cuba de espessura apropriada. Faz-se ao mesmo tempo, passando-se por 
tôdas as fases da determinação, um branco, que serve de líquido de compensação.

A concentração do cálcio é dada pela fórmula seguinte:

$\mathrm{mg}$ de cálcio $=\frac{0.471 \times \mathrm{k} \mathrm{x} \mathrm{V}}{\mathrm{v}}$

em que

$\mathrm{k}=$ coeficiente de extinção

$\mathrm{V}=$ volume total da solução corada

$\mathrm{v}=$ volume da substância posta em análise $\left(\mathrm{cm}^{3}\right)$.

DETERMINAÇÃO DO CÁlCIO EM ALGUNS PRODUTOS DE ORIGEM BIOLÓGICA.

Para determinar o cálcio total, a incineração por via úmida foi a usada, de acôrdo com o que se descreveu em (14). Depois de findo 0 ataque nitro-perclórico, de ter sido eliminado todo o ácido perclórico e de se haverem destruido os percloratos formados, de conformidade com a técnica descrita, o resíduo se dissolve em $\mathrm{ClH}$ o.lN, de conformidade com o que se descreve em (13).

DETERMINAĈ̣̃O DO CÁlCIO NA SOLUÇÃo DAS CINZAS. Uma parte aliquota da solução clorídrica das cinzas passa-se para um tubo de centrífuga de vidro Pyrex, de forma cônica e de diâmetro reduzido na extremidade afilada, e trata-se exatamente como se descreveu em "Método". Faz-se ao mesmo tempo, rigorosamente sob as mesmas condições, um branco dos reativos que corresponda exatamente a tôdas as fases da dosagem e que servirá de líquido de compensação.

ReProdutibilidade dos Resultados. A determinação do cálcio no sôro humano, v. g., pode realizar-se por meio da precipitação direta desse elemento sob forma de $\left(\mathrm{PO}_{4}\right)_{2} \mathrm{Ca}_{3}(3)$, visto a quantidade de interferentes precipitáveis pela oxina em meio ácido ser pràticamente desprezivel no caso, e a de magnésio ser tambem de tal forma reduzida que êste se pode isolar como $\mathrm{Mg}(\mathrm{OH})_{2}$ de sorte a eliminar-se a influência dêste elemento. Na dosagem do cálcio no sangue (hemolinfa) dos crustáceos da água salgada, porém, tôdas as separações descritas em (13) devem ser realizadas, pois a presença de corpos interferentes, em quantidades importantes, tem que ser devidamente considerada. A água do mar, graças particularmente à percentagem relativamente alta de magnésio, requer que o cálcio seja isolado, de modo a eliminar-se a ação prejudicial, daquele corpo. Êsses exemplos mostram a necessidade de estudos preliminares, do material com que se trabalha, afim de fazer-se aplicação criteriosa do método. 
Apezar de ser mais simples e mais seguro isolar-se o cálcio diretamente como $\left(\mathrm{PO}_{4}\right)_{2} \mathrm{Ca}_{3}$, no sôro do sangue dos grandes animais domésticos, v. g., o quadro seguinte mostra a possibilidade de se alcançarem bons resultados por meio da precipitação prévia do $(\mathrm{COO})_{2} \mathrm{Ca}$ e ulterior transformação desse sal em $\mathrm{Cl}_{2} \mathrm{Ca}$.

\section{QUADRO I}

Determinação do cálcio em sôro de sangue de cavalo

\begin{tabular}{|c|c|c|c|c|c|c|}
\hline $\begin{array}{l}\text { Quantidade } \\
\text { de sôro to- } \\
\text { mada para } \\
\text { a análise } \\
\text { cm3 }\end{array}$ & $\begin{array}{l}\text { Volume da } \\
\text { solucão } \\
\text { corada } \\
\text { cm33 }\end{array}$ & $\begin{array}{c}\text { Espessura } \\
\text { da cuba } \\
\text { usada } \\
\text { ems }\end{array}$ & D & $\mathrm{E}$ & k & $\begin{array}{c}\text { Ca. per } \\
100 \mathrm{~cm} 3 \\
\text { de sôro } \\
\text { mg }\end{array}$ \\
\hline 0.1 & 7.5 & 1 & 42 & - & 0.377 & 13.32 \\
\hline 0.1 & 10 & 2 & 48 & 0.553 & 0.277 & 13.05 \\
\hline 0.2 & 10 & 1 & 27 & - & 0.569 & 13.40 \\
\hline 0.2 & 10 & 1 & 28.6 & - & 0.544 & 12.81 \\
\hline 0.3 & 10 & 1 & 14 & - & 0.854 & 13.41 \\
\hline 0.3 & 10 & 1 & 15 & - & 0.824 & 12.94 \\
\hline 0.4 & 10 & 0.5 & 26.6 & 0.575 & 1.150 & 13.54 \\
\hline 0.4 & 10 & 0.5 & 28 & 0.553 & 1.106 & 13.02 \\
\hline 0.5 & 10 & 0.5 & 20 & 0.699 & 1.398 & 13.17 \\
\hline 0.5 & 10 & 0.5 & 21.4 & 0.670 & 1.340 & 12.62 \\
\hline 0.6 & 10 & 0.5 & 14 & 0.854 & 1.708 & 13.41 \\
\hline 0.6 & 10 & 0.5 & 15 & 0.824 & 1.648 & 12.94 \\
\hline
\end{tabular}

Média . . . . . . . . . 13,14

Erro médio . . . . . . . . 0.284

Erro padrão . . . . . . . . 0.082

Coeficiente de variação . . . . $2.161 \%$

No caso do sôro obtido do Callinectes dance Smith, porém, é necessário que se separem os interferentes precipitáveis por meio da oxina em meio ácido, como também é o caso do sangue humano, e que, devido à percentagem relativamente alta, de magnésio, se tomem as precauções necessárias para reduzir-se tanto quanto possível o fenômeno da coprecipitação.

O material usado para a organização do quadro seguinte, resultou da mistura da hemolinfa de vários animais. 
R. S. Pereira - Determinação de pequenas quantidades de cálcio

QUADRO II

Determinação do cálcio no sôro do sangue de Callinectes danae Smith

\begin{tabular}{|c|c|c|c|c|c|c|}
\hline $\begin{array}{c}\text { Quantidade } \\
\text { de sôro to- } \\
\text { mada para } \\
\text { a análise } \\
\text { cm3 }\end{array}$ & $\begin{array}{l}\text { Volume da } \\
\text { solucão } \\
\text { corada } \\
\text { cm3 }\end{array}$ & $\begin{array}{l}\text { Espessura } \\
\text { da cuba } \\
\text { usada } \\
\text { ems }\end{array}$ & D & $\mathbf{E}$ & k & $\begin{array}{c}\text { Ca. per } \\
100 \mathrm{~cm}^{3} \\
\text { de sôro } \\
\text { mg }\end{array}$ \\
\hline 0.02 & 10 & 2 & 33 & 0.482 & 0.241 & 56.76 \\
\hline 0.02 & 10 & 2 & 32 & 0.495 & 0.248 & 58.40 \\
\hline 0.03 & 10 & 1 & 43 & - & 0.367 & 57.62 \\
\hline 0.03 & 10 & 1 & 42 & - & 0.372 & 58.40 \\
\hline 0.04 & 10 & 1 & 32.4 & - & 0.490 & 57.70 \\
\hline 0.04 & 10 & 1 & 31 & - & 0.509 & 59.93 \\
\hline 0.05 & 10 & 1 & 24 & - & 0.620 & 58.40 \\
\hline 0.05 & 10 & 1 & 24.6 & - & 0.610 & 57.46 \\
\hline 0.06 & 10 & 1 & 18 & - & 0.745 & 58.46 \\
\hline
\end{tabular}

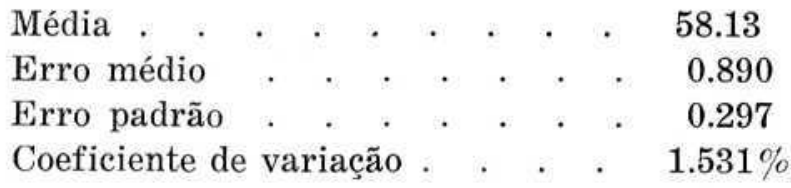

\section{SUMMARY}

A modification of Hirth's method for calcium is presented. The important cations interfering in the precipitation of calcium oxalate aluminium, copper, manganese, iron, zink, etc. - are separated as the oxinate in a buffered acid solution. In view of determining calcium in blood of marine animals, the method of Hirth for separating calcium as the oxalate has been modified so as to avoid alkalinizing the sample solution.

Calcium first separated as the oxalate is finally isolated as the phosphate, the phosphorus contents of which is determinated photometrically.

\section{BIBLIOGRAFIA}

1 - MANLY, R. S. - 1939 - A list of micromethods for the determination of calcium and phosphate. Mikrochemie, 27: 145-153

2 - Robertson, J. D. and D. A. WeBB - 1939 - The micro-estimation of sodium, potassium, calcium, magnesium, chloride, and sulphate in sea-water and the body fluids of marine animals. J. Exp. Biol., 26: 155-77

3 - RoE, J. H. and B. B. KAHN - 1929 - The colorimetric determination of blood calcium. J. Biol. Chem., 81: 1-8 
4 - BERG, R. - 1938 - Die analytische Verwendung von o - Oxychinolin (Oxin) und seiner Derivate. Die Chemische Analyse, 34: Band. Stuttgart, Ferdinand Enke

5 - Yoshimatsu, Shun-IChi - 1930 - A new colorimetric method for the determination of calcium with 0.1 ce of blodd. Tohoku J. Exp. Med., 15: $355-62$

6 - Kolthoff, I. M. and E. B. SANDEll -1943 - Text-book of quantitative inorganic analysis - págs. 345 e seg. - New York, Macmillan

7 - SENDroy, J. - 1942 - Photoelectric microdetermination of oxalic acid and calcium and its application to micro and ultramicro-analysis of serum. J. Biol. Chem. 144: 243-58

8 - SENDROY, J. - 1944 - Determination of serum calcium by precipitation with oxalate. J. Biol. Chem., 152: 539-56

9 - in Georges Denigès, L. Chelle e A. Labat - 1931 - Précis de Chimie Analytique, 6.ème ed., Tome 2. págs. 135-6- - Paris, Maloine

10 - Brigs, A. P. - 1924 - Some applications of the colorimetric phosphate method. J. Biol. Chem., 59: 255-64

11 - Kuttner, T. and H. R. Cohen - 1927 - Micro colorimetric studies I: A molybdic acid, stannous chloride reagent. The micro estimation of phosphate and calcium in pus, plasma and spinal fluid. J. Biol. Chem., 75: $517-31$

12 - Salomé Pereira, R. - 1944 - Sôbre a determinação fotométrica do cálcio no sôro sanguíneo. Rev. bras. Biol., 4: 263-70

13 - Salomé Pereira, R. - 1945 - Sôbre a determinação fotométrica do magnésio nos produtos de origem biológica. Rev. Fac. Med. Vet., S. Paulo, 3 (1)

14 - SAlomé Pereira R. - 1945 - Photometric determination of potassium in biological-materials. J. Biol. Chem. 160: 617-29 